\title{
Peptide Ligation via Suzuki-Miyaura Cross-Coupling Reaction
}

\author{
Tae-Kyung Lee, Bikash Manandhar, and Jung-Mo Ahn* \\ Department of Chemistry and Biochemistry, University of Texas at Dallas, Richardson, TX, 75080, USA
}

\section{Introduction}

Functions of peptides can be improved or new ones be conferred by introducing molecules of different properties. Conjugation of peptides with cognate peptides, cell-permeable peptides, and PEG chains may enhance affinity to targets, cellular uptake, and metabolic stability, respectively. Furthermore, incorporation of chemical probes, such as fluorescent dyes and affinity tags, to peptides provides a useful tool for studying biological systems. Suzuki-Miyaura reaction, a palladium catalyzed crosscoupling reaction between a boronic acid and an organohalide or sulfonate, has a great potential inpeptide ligations due to advantages like bio-orthogonality and tolerance toward a broad range of functional groups [1,2]. However, the Suzuki-Miyaura reaction has been seldom used in peptide synthesis presumably because of relatively incompatible reaction conditions like a high reaction temperature in organic solvents [3-6]. In this study, we developed a method for chemoselective and bioorthogonal ligation of peptides via the Suzuki-Miyaura reaction. We also employed the method to conjugate various chemical probes to peptides.

\section{Results and Discussion}

We first studied the impact of bases and solvents at a range of temperature on the cross-coupling reaction of the iodo-peptide and the peptide boronic acid (Figure 1a). As a base, $\mathrm{K}_{2} \mathrm{CO}_{3}$ was found to be quite efficient compared to $\mathrm{KF}$ and $\mathrm{Et}_{3} \mathrm{~N}$. Screening of solvents showed that aqueous DMF, 2,2,2trifluoroethanol (TFE) and 10\% sodium dodecyl sulfate (SDS) solutions afforded the cross-coupled peptides in good yields, whereas $6 \mathrm{M}$ urea solution was not effective for the ligation. In particular, the coupling reaction at $40^{\circ} \mathrm{C}$ in $10 \%$ aqueous SDS solution achieved a remarkably high yield $(95 \%$, Figure 1a). The concentration of SDS can be lowered to $0.3 \%$ without compromising the high yield. On the other hand, Triton and glycerol [5] were less efficient for the cross-coupling reactions. With the optimized reaction conditions in hand $\left(\mathrm{K}_{2} \mathrm{CO}_{3}, 10 \% \mathrm{SDS}\right)$, we then evaluated various Pd catalysts such as $\mathrm{PdCl}_{2}$ (dppf), $\mathrm{Pd}\left(\mathrm{PPh}_{3}\right)_{4}, \mathrm{PdCl}_{2}(\mathrm{dba})_{3}, \mathrm{Pd}(\mathrm{OAc})_{2}$, and $\mathrm{PdCl}_{2}\left(\mathrm{PPh}_{3}\right)_{2}$ for the efficiency of the ligation reaction. Whereas all of the tested catalysts gave the cross-coupled peptide in moderate to high yield, $\mathrm{PdCl}_{2}$ (dppf) turned out to be the most effective one.

(a)
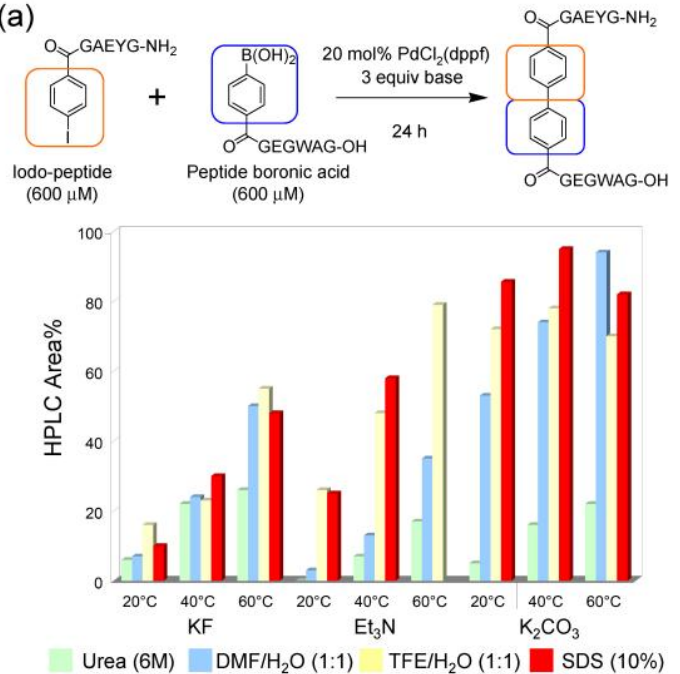

(b)
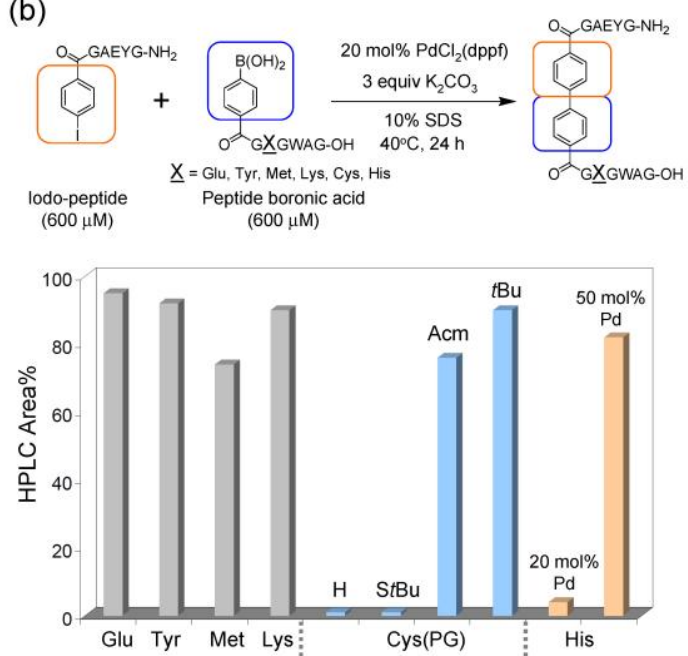

Fig. 1. Optimization of Suzuki-Miyaura cross-coupling reactions of peptides. (a) Screening of base, solvent, and temperature. (b) Effect of amino acids on the cross-coupling reaction. 

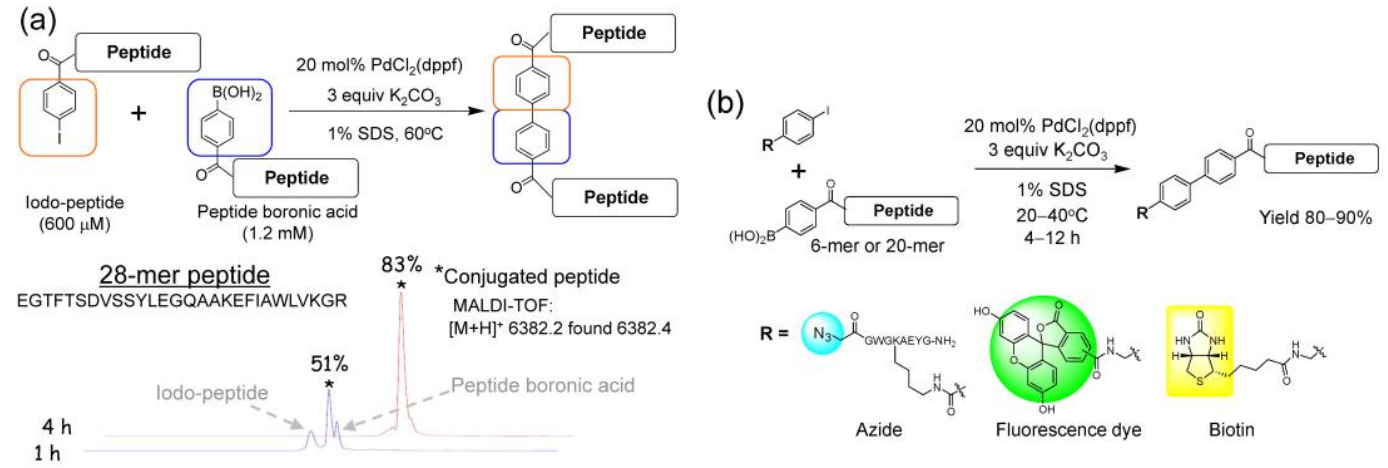

Fig. 2. (a) Suzuki-Miyaura ligation of long peptides. (b) Orthogonal labeling of peptides.

In order to study the effect of amino acids on the cross-coupling reaction, we prepared a series of peptide boronic acids bearing various side chain functional groups (Figure 1b). Many amino acids such as Glu, Tyr, Met, and Lys were found to be compatible to the cross-coupling reaction giving 74-95\% yield. However, Cys and His were not tolerated for the ligation presumably due to chelation of palladium with thiol and imidazole. Three protecting groups of Cys, such as $t$-butylthio $(\mathrm{St} \mathrm{Bu})$, acetamidomethyl $(\mathrm{Acm})$, and $t$-butyl $(t \mathrm{Bu})$ were thus examined. Whereas a Cys $(\mathrm{S} t \mathrm{Bu})$-peptide was not successful in cross-coupling reaction, peptides possessing thioethers such as $\mathrm{Cys}(\mathrm{Acm})$ or $\mathrm{Cys}(t \mathrm{Bu})$ afforded the ligated peptide in $76-90 \%$ yield at $60^{\circ} \mathrm{C}$. On the other hand, higher Pd loading $(50$ mol\%) converted a His-containing peptide to the ligated peptide in high yield $(82 \%)$ at $60^{\circ} \mathrm{C}$ (Figure $1 \mathrm{~b}$ ). We then carried out ligation reactions between long peptides (Figure 2a). Two 28-mer peptides were successfully ligated generating a 56-mer peptide in $83 \%$ yield. These results are notable as few methods were reported for efficient ligation between two long peptides.

The Suzuki-Miyaura ligation would be of great interest for multiple conjugations of peptides if it can be orthogonal to existing ligation methods. To investigate the feasibility of orthogonal ligations, we examined the compatibility of an azide, a reaction component of the 1,3-dipolar cycloaddition and the Staudinger ligation, to the Suzuki-Miyaura ligation reaction (Figure 2b). The azido-bearing peptide gave the ligated peptide in $90 \%$ yield (Figure $2 \mathrm{~b}$ ). In addition to peptide-peptide ligation, conjugation of fluorophores or affinity tags to peptides is also of high value in biomedical study. Fluorescein- and biotin-containing aryl iodides were efficiently conjugated to 20 -mer peptide in $80 \%$ and $88 \%$ yield, respectively (Figure $2 b$ ).

In summary, we have optimized reaction conditions for Suzuki-Miyaura cross-coupling of peptides. Aqueous solutions containing SDS were found to be important for high-yielding ligation of long peptides. It also facilitated introduction of an affinity tag or a fluorescent probe to peptides. The reaction was found to be compatible with many functional groups, such as azide and S-protected thiol, and these render the Suzuki-Miyaura cross-coupling useful for multiple conjugations of peptides and proteins, together with conventional conjugation reactions.

\section{Acknowledgments}

This work was supported in part by the Welch Foundation (AT-1595), Juvenile Diabetes Research Foundation (37-2011-20), and Cancer Prevention and Research Institute of Texas (RP100718, RP120717-P4).

\section{References}

1. Miyaura, N., et al. Chem. Rev. 95, 2457-2483 (1995), http://dx.doi.org/10.1021/cr00039a007

2. Alonso, F., et al. Tetrahedron 64, 3047-3101 (2008), http://dx.doi.org/10.1016/j.tet.2007.12.036

3. Doan, N., et al. J. Comb. Chem. 10, 44-51 (2008), http://dx.doi.org/10.1021/cc700128b

4. Ahn, J.-M., et al. Chem. Commun. 480-481 (2003), http://dx.doi.org/10.1039/B210696E

5. Ojida, A., et al. Tetrahedron Lett. 46, 3301-3305 (2005), http://dx.doi.org/10.1016/j.tetlet.2005.03.094

6. Dumas, A., et al. Angew. Chem. Int. Ed. 52, 3916-3921 (2013), http://dx.doi.org/10.1002/anie.201208626 